\title{
Belgeo
}

Revue belge de géographie

4 | 2021

Relating physical and human geography

\section{Charting the divide: a science-mapping perspective on the relationship between human and physical geography}

Cartographier la fracture: un point de vue bibliométrique sur la relation entre géographie humaine et physique

\section{Emiliano Tolusso}

\section{OpenEdition}

\section{Journals}

\section{Electronic version}

URL: https://journals.openedition.org/belgeo/52692

DOI: 10.4000/belgeo.52692

ISSN: 2294-9135

Publisher:

National Committee of Geography of Belgium, Société Royale Belge de Géographie

\section{Electronic reference}

Emiliano Tolusso, "Charting the divide: a science-mapping perspective on the relationship between human and physical geography", Belgeo [Online], 4 | 2021, Online since 01 March 2022, connection on 05 March 2022. URL: http://journals.openedition.org/belgeo/52692 ; DOI: https://doi.org/10.4000/ belgeo. 52692

This text was automatically generated on 5 March 2022.

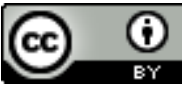

Belgeo est mis à disposition selon les termes de la licence Creative Commons Attribution 4.0 International. 


\section{Charting the divide: a science- mapping perspective on the relationship between human and physical geography}

Cartographier la fracture: un point de vue bibliométrique sur la relation entre géographie humaine et physique

Emiliano Tolusso

\section{Introduction: on integration, similarity, and scientific relevance}

1 Many words have been written on the relationship between human and physical geography, and the divide is explored in its epistemological, social, and cultural depths. This issue itself represents another attempt to clarify the problem: how should we, as geographers, look at our counterparts? In this paper, I am looking at the phenomenon on a documental level, i.e., I am interested in the material production of literature and the features it bears. The newest stances proposed by the emerging disciplinary strain of Critical Physical Geography (Lave, 2015) are renewing the interest over a long-troubled question, following the emergence of global socio-environmental problems. In their account, Lave et al. reject the idea that the fundamental unity of geography as a discipline can be explained in an inertial legacy of the past (Johnston, 2012) and propose a series of epistemological and pragmatical reasons for pursuing an integration between the two hitherto separate fields of geography. In their proposition, adopting a critical stance is entirely necessary to gain the explanatory power needed to shed light on environmental processes.

2 As the proposition gained momentum in 2015, it picked up the threads of a long, polarizing debate. Professionals from both sides of the divide chimed in the discussion, 
delving into the potential benefits and shortcomings of integration between the disciplines. The result is a compelling discussion, inscribed in a cyclically recurring theme in the literary debate over geography, connecting - inter alia, and limiting our scope to the Anglo-American debate - the work of the likes of William Bunge (1962), Doreen Massey (1999), Nicholas Clifford (2002), Rob Ferguson (2003) and Andrew Goudie (2017). In such a landscape, Lave's and associates' work poses a turning point in the discussion, as they point effectively to many ongoing research pieces that practice a form of integration, instead of advocating for it, or moving within a merely theoretical framework. Supposing the claim is read under the lens of philosophy and sociology of science, the explicit invitation is to work on a strain of boundary research ${ }^{1}$ (Gyern, 1983) - or even transboundary - that could overcome the Kuhnian problem of incommensurability between different scientific paradigms (Kuhn, 1962). In this perspective, Lave et al. point at several institutional, material, and political constraints that need to be reworked and reshaped to allow the melding of a new form of integrated knowledge.

Among them, the publishing practices assume a fundamental role.

"In our experience, it can be very hard to publish work that combines physical science and critical engagement with social theory and power relations. New journals are one possibility, but a better solution would be for editors and associate editors of existing journals to change the ways in which they select and recruit reviewers" (Lave et al., 2014, p. 7).

Beyond the anecdotical, Lave et al. offer little evidence about the degree of fragmentation of the publishing fields, leaving a question mark around the existence of bridges connecting the two fields. How far are we? Or, rephrasing the opening question, are we even looking for the knowledge produced by our counterparts in our everyday academic life? Among the many voices contributing to the still ongoing discussion on the divide, a bibliometric approach is notably lacking. The only examples are given by Ferguson (2003), in his reply to the notorious Thrift's paper "The future of Geography" (2002), and Bodman (1991). The former is a rare example of a documental account of the divide, in which the author inquires on the difference in publishing behaviours between human and physical geographers, as supposed by Thrift, with a close look at empirical data on publications. By contrast, the latter argues that citation data can be fruitfully employed to chart the structure and hierarchy of geography as an academic discipline. I am proposing a slightly different perspective on the matter within these pages, as I aim to chart the current degree of intellectual contact and engagement between the two disciplines. I am neither delving into citation frequencies as a tool to shed light on the social pyramid of academic geography nor confronting different publishing cultures; rather, my interest lies in the citational relationships that connect human and physical geographers, and specifically in when, where, and how much they cite each other. Bodman's account suggests that citations are a measure of influence. I am advocating for a small semantic shift: citation is to be read, at least in the context of these pages, as a measure of relevance: in a multidisciplinary intellectual landscape, citing a piece of knowledge produced in a different scientific community tells us about what is intellectually relevant in our field of enquiry, and, indirectly, what is not. Hence, I am trying to reconstruct the network of citations of both Human (HG) and Physical Geography (PG) to understand (I) what pieces of scientific knowledge born on one side of the academic fence are relevant to the other side, and (II), how 
scientific products are mobilised and employed as building blocks for further sciencemaking endeavours in different fields.

In such endeavour, I am borrowing some instruments from the domain of scientometrics (Leydesdorff, Milojević, 2015) and science-mapping. Science mapping is a young research topic at the crossroad of scientometrics, information visualization, network analysis, and sociology of science (Börner, Chen \& Boyack, 2005; Börner, Theriault \& Boyack, 2015). It aims to display the structure and dynamics of scientific knowledge by using 2- or 3-d visualizations, known as "science maps" (Chen, 2017). This methodology can reveal itself extraordinarily well-equipped to chart the bridges that still stand in connection between the two sides.

\section{Charting science: a methodological remark on two studies}

6 Techniques, methodologies, and technologies for mapping science are various and widely addressed in scientific literature (Petrovich, 2020). For the purpose of this paper, I built an archive of every Web of Science (WoS)-indexed publication and processed it with VOSviewer, a freely available science mapping tool developed by Ludo Waltman and Nees Jan van Eck at the Center for Science and Technology Studies (CWTS) in Leiden (van Eck, Waltman, 2007). VOSviewer allows the user to build science maps and arrange the results according to different sets of mapping rules.

7 I structured this paper around two complementary studies. One looks at the citational relationship detectable in a sample of HG and PG journals, while the other focus on the use made by a relevant interdisciplinary journal of the information produced from HG and different categories of scientific journals, via co-citations.

8 For the first case study, I selected 10 journals for each field of enquiry. Generally, data for the mapping is retrieved from a citation database, i.e., a database that collects the meta-data of scientific publications (authors, title, publication year, etc.) along with their references and citation links with subsequent works (citing articles). Clarivate's WoS and Elsevier's Scopus are the main resources for this kind of data ${ }^{2}$. As a measure for preserving data's structure, I restricted the field of potential analysis to WoSindexed journals only.

9 Note that, in terms of journal indexing and academic publishing, the field is historically dominated by British scholars and institutions (Paasi, 2005), and the general publication landscape mirrors this imbalance. Taking Scimago Journal \& Rank $^{3}$ as a reference proves the claim, as the great majority of journals ranked in or above the second quartile (Q2) in SJR (Scimago Journal Rank indicator ${ }^{4}$ ) is either British or American in both disciplines. Research has already shown the distortive consequences of basing a bibliometric study solely on the head of the Lotka curve ${ }^{5}$ (Saam, Reiter, 1999) in terms of international representation (Paasi, 2005, p. 769). Hence, selecting a sample composed of top journals alone is risky, as it might suppress national variability among scientific communities and offer a very partial reconstruction of the relationship. The samples are therefore composed of a majority of Q1 British-American journals and a variable quota of lower quartiles journals of different nationalities. Despite the underpinning principle remain the same, the selection strategy must face two very different publication landscapes. The case of Human Geography (HG) presents 
several specialistic journals that usually concentrate the bulk of the literature produced by human geographers (Ferguson, 2003). The selection process considered both tout-court Geography journals ${ }^{6}$ as well as specialisms in HG.

The selected journals are the following (nationality in brackets):

1. Progress in Human Geography (UK)

2. Geografiska Annaler Series B - Human Geography (SWE)

3. Transactions of the Institute of British Geographers (UK)

4. Annals of the American Association of Geographers (USA)

5. Dialogues in Human Geography (UK)

6. Geographical Journal (UK)

7. Geography Compass (UK)

8. Acme (CAN)

9. Fennia (FIN)

10. Geoforum (UK)

11 On the contrary, Physical Geography (PG) displays different publishing behaviour. Following Ferguson's account, the scientific community aims to publish its work in general, wide-scope scientific journals or multidisciplinary specialisms, and subdisciplinary scientific periodical (Id., 2003). The sample take consideration only of the last two categories. Hence, wide-scope, generalist scientific journals are not a feasible unit of analysis for the task, diluting the citational flow between the two disciplines into a vast multidirectional flow. The journals identified are either explicitly addressing PG or are part of Ferguson's original dataset.

Hence, the selected journals are the following:

1. Progress in Physical Geography (UK)

2. Geografiska Annaler Series A - Physical Geography (SWE)

3. Physical Geography (UK)

4. Geomorphology (NL)

5. Earth Surface Processes and Landforms (UK)

6. Hydrological Processes (UK)

7. Catena (NL)

8. Land $(\mathrm{CH})$

9. Cryosphere (GER)

10. Hydrology and Earth System Science (GER)

13 Articles' metadata have been retrieved for each journal, ranging from 1985 to 2020 . These data alone are a valuable source of information about both disciplines' research dynamics: the name of authors, institutions, main topics of enquiry can all be traced with a science mapping approach. More importantly, the data allow the researcher to trace the citing relationship that marks the two distinctive disciplines. Our interest lies in the citational flow that connects the datasets with the broader scientific panorama. Starting from the initial dataset, I gathered all the citing articles, i.e., all the articles that cite one or multiple articles from the initial dataset, to map the number of citations and the disciplinary domains toward which the citations flow ${ }^{7}$. In other words, the methodology enables the researcher to trace which disciplines employ human and physical geography as a source of information for producing new knowledge. 
Figure 1. Design of the first study.

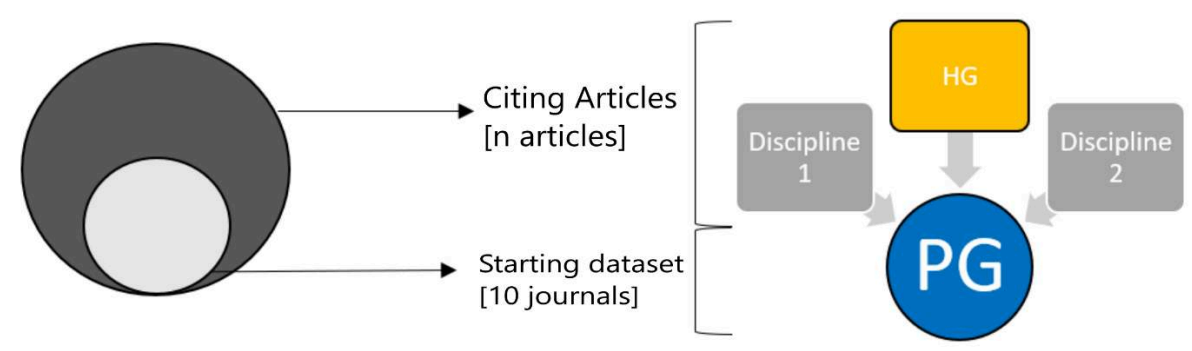

Left: Starting datasets (light grey) and citing references (dark grey). Right: Isolating HG citations from the overall citational flow generated by the PG dataset. The same process has been applied on the HG dataset.

The sample has been analysed via WoS built-in tools to break down the citing articles' main categories and obtain a complete analysis of the citation flows that cross the disciplines. It is then possible to isolate the share of citations moving from one geography to the other and retrieve the raw data needed to map the citation flow. Citational maps are constructed for every journal regarding the citations received from the "other geography". The citation datasets are then aggregated and analysed. For the sake of this study, the functional relationships among the nodes are traced via

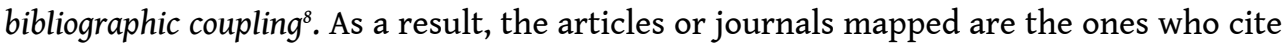
articles published by one of the journals of the other dataset, while their relative position and the strength (graphically presented as the width of the line) of their connections are determined by the share of references they have in common. The analysis aims at:

1. tracing the actual dimension of the citation flows between the two geographies;

2. mapping the journals serving as harbours for citation flows;

3. mapping the main topics that incorporate scientific information coming from the other side of the divide.

15 The second study is structured around a complementary perspective. Once obtained a picture of the journals' direct citational scopes, the interest turns to an external perspective. I focused on a middle ground publication - a journal which field of interest crosses but does not entirely belong to the discipline - to evaluate how and how much HG journals are combined with different disciplinary and multidisciplinary journals in the construction of new, potentially integrative knowledge. Co-citation analysis (Small, 1973) provides a valuable conceptual tool to engage in such evaluations. In cocitation analysis, the similarity of publications is measured based on the number of times they are cited together in the references of a set of other publications ${ }^{10}$. If publications are frequently cited together, they are likely to be more related than if they are seldom or never cited together.

To achieve the task, I isolated all the articles published in Global Environmental Change - Human and Policy Dimensions from its birth to today. The journal aims to publish articles dissecting the social drivers or consequences of environmental change or social and policy processes that seek to address environmental change problems. The journal provides a clear benchmark, as its task requires the employment of geo- and bioscientific information to generate new humanistic, social, and political analyses. 
Therefore, the study aims to evaluate the frequency of co-citation of papers form HG journals and different categories of scientific journals (fig. 2).

Figure 2. Design of the second study.

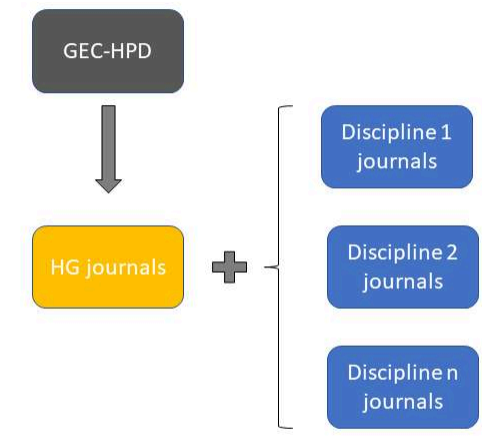

Co-citation of HG journals with different disciplinary journals

\section{Tracing the citational flows between HG and PG in the samples}

The first exploratory step in the study consists in a quantification of the citational flows moving from one geography to the other. WoS indexed articles are retrieved for every journal in the datasets and employed in the quantification of the share of citations directed to the other geography (table 1, figure 2). Note that table 1 reports on the number of articles that are citing the initial dataset (citing articles) and the share of such articles that are indexed as PG or HG in WoS database.

Table 1. The study's dataset.

\begin{tabular}{|l|l|l|l|l|l|l|l|}
\hline & Journal & Category & Country & $\begin{array}{l}\text { Published } \\
\text { articles }\end{array}$ & $\begin{array}{l}\text { Citing } \\
\text { articles }\end{array}$ & $\begin{array}{l}\text { citing by } \\
\text { PG }\end{array}$ & \% \\
\hline $\mathbf{1}$ & Progress in Human Geography & HG & UK & 4272 & 45741 & 681 & 1.49 \\
\hline $\mathbf{2}$ & Geografiska Annaler Series B & HG & SWE & 778 & 8768 & 127 & 1.45 \\
\hline $\mathbf{3}$ & $\begin{array}{l}\text { Transactions of the Institute of } \\
\text { British Geographers }\end{array}$ & HG & UK & 2678 & 39006 & 1721 & 4.41 \\
\hline $\mathbf{4}$ & $\begin{array}{l}\text { Annals of the American } \\
\text { Association of Geographers }\end{array}$ & HG & USA & 597 & 3074 & 188 & 6.12 \\
\hline $\mathbf{5}$ & Dialogues in Human Geography & HG & UK & 428 & 1000 & 10 & 1.00 \\
\hline $\mathbf{6}$ & Geographical Journal & HG & UK & 9719 & 20650 & 1647 & 7.98 \\
\hline
\end{tabular}




\begin{tabular}{|c|c|c|c|c|c|c|c|}
\hline 7 & Geography Compass & HG & UK & 257 & 1900 & 35 & 1.84 \\
\hline 8 & Acme & HG & CAN & 200 & 928 & 5 & 0.54 \\
\hline 9 & Fennia & HG & FIN & 107 & 223 & 9 & 4.04 \\
\hline \multirow[t]{3}{*}{10} & Geoforum & HG & UK & 3437 & 47793 & 646 & 1.35 \\
\hline & TOTAL & & & 22473 & 169083 & 5069 & 3.0 \\
\hline & Journal & Category & Country & Articles & citing & $\begin{array}{l}\text { citing by } \\
\text { HG }\end{array}$ & $\%$ \\
\hline 11 & Progress in Physical Geography & PG & UK & 749 & 17483 & 842 & 4.82 \\
\hline 12 & Geografiska Annaler Series A & PG & SWE & 1172 & 14956 & 528 & 3.53 \\
\hline 13 & Physical Geography & PG & UK & 998 & 8307 & 383 & 4.61 \\
\hline 14 & Geomorphology & PG & NED & 6853 & 86288 & 1869 & 2.17 \\
\hline 15 & $\begin{array}{l}\text { Earth Surface Processes and } \\
\text { Landforms }\end{array}$ & PG & UK & 4715 & 62680 & 1416 & 2.26 \\
\hline 16 & Hydrological Processes & PG & UK & 7559 & 107447 & 977 & 0.91 \\
\hline 17 & Catena & PG & ND & 5039 & 61725 & 965 & 1.56 \\
\hline 18 & Land & PG & SWI & 776 & 2318 & 154 & 6.64 \\
\hline 19 & Cryosphere & PG & GER & 1695 & 15394 & 122 & 0.79 \\
\hline 20 & $\begin{array}{l}\text { Hydrology and Earth System } \\
\text { Sciences }\end{array}$ & PG & GER & 4408 & 66935 & 610 & 0.91 \\
\hline & TOTAL & & & 33964 & 443533 & 7866 & 1.77 \\
\hline
\end{tabular}

18 The HG dataset consists of 22,473 articles, while 33,964 articles compose PG's set. The articles in the HG dataset were cited by 169,083 articles, while those form the PG dataset appeared in the references of 443,533 articles.

Citation flows between the two geographies, as expected, are a residual amount of the totality of citations traced in the fields (fig. 3). On average $3 \%$ of the citations of articles from HG dataset were made in PG articles. Tout-court geographical journal as the Transactions, Annals, Geographical Journal and Fennia show higher values, which probably reflect the fact that they publish a minority of PG papers. When excluded, the citation share drops to $1.42 \%$. On the opposite side, $1.77 \%$ of the total citations of papers published in the PG dataset are found in HG journals, with lower values for subdisciplinary journals: Hydrology and Earth System Sciences, Cryosphere, Hydrological 
Processes and Landforms. On the contrary, wide scope journals, as Progress in PG, or Land display higher values.

The analysis can be extended by adding a time dimension. The citation data were then disaggregated on an annual basis and expressed as a simple percentage of the citations obtained by individual journals from the "other geography" over the total volume of citations they received. Figure 3 shows percentage rates over a 6-year time window for all ten HG journals and a 30-plus year reconstruction of recorded trends for journals with longer time series ${ }^{11}$.

Figure 3. \% values of HG journals over a 6-year window (2015-2020) and over a 31-year window (1990 to 2020).

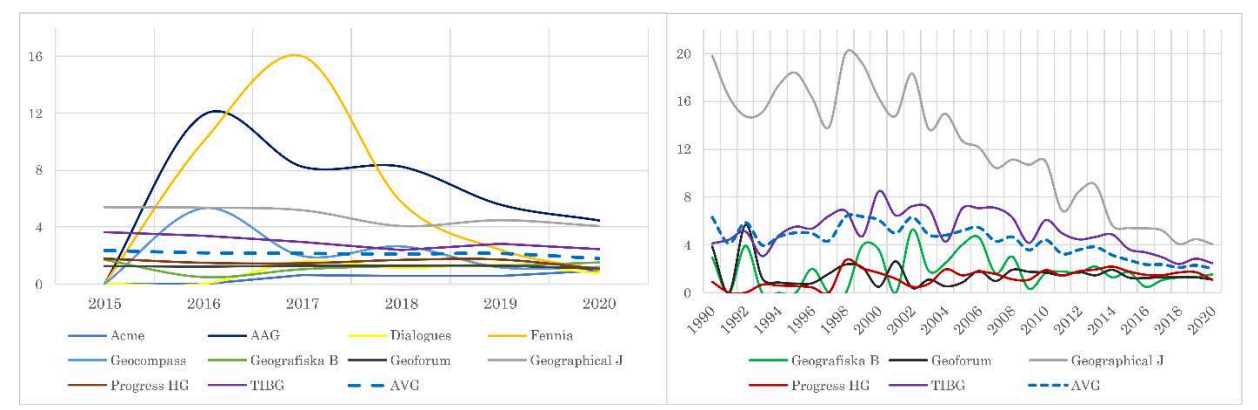

The short time window shows converging trends for all journals considered, apart from Fennia between 2016-2018, and the Annals, which show consistently higher than average values. In the case of journals with a longer time window, the Geographical Journal stands out, reaching values of $20 \%$ several times, before dropping drastically since the early 2000s. A comparative analysis of the two timeframes demonstrates that the most recent data show lower average values than those from the 1990 s. Figure 4 repeats the same experiment with PG journals.

Figure 4. \% values of PG journals over a 6-year window (2015-2020) and over a 31-year window (1990 to 2020).

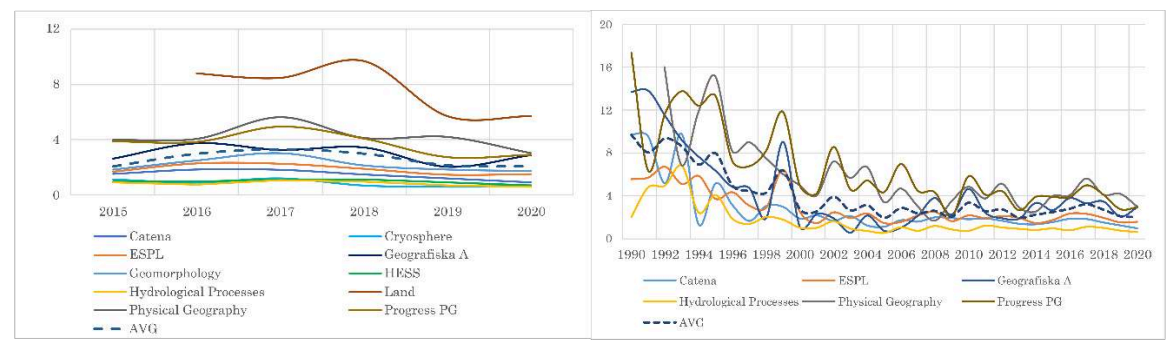

In this case, the short time window displays the peculiarity of Land ${ }^{12}$, which is cited in HG journals more consistently and frequently than the overall six-year average, in line with its mission ${ }^{13}$.

A look at the long term, on the other hand, shows a downward trend, which can be clearly seen, for example, in the decrease of the journals Physical Geography and Progress in Physical Geography. 


\section{largely different disciplines, and the time-series are testifying a deepening of an already notable divide. However, a point of contact exists and should be explored in its constitutive elements.}

samples confirm the existence of an intellectually broad space separating two

\section{Mapping the bridges: where, and why, PG cites HG}

The citing articles can be employed effectively to map how and why PG cites HG or vice versa. A first interesting question to ask is where the two disciplines intertwine. Which are the journals in the field of HG and PG that host the highest share of citation towards the "other" geography?

Figure 5 maps PG journals citing articles from the original HG sample. The map identifies the 78 PG journals that cite papers from the original HG dataset ${ }^{14}$ and organizes the spatial configuration via bibliographic coupling. As a result, the connections between the journals express the similarity of their bibliographic references. Additionally, a cluster analysis based on the modularity function ${ }^{15}$ (Brandes et al., 2008) superimposes a classification over the structure, helping the identification of different families of journals.

Figure 5. Network map of PG journals citing HG articles.

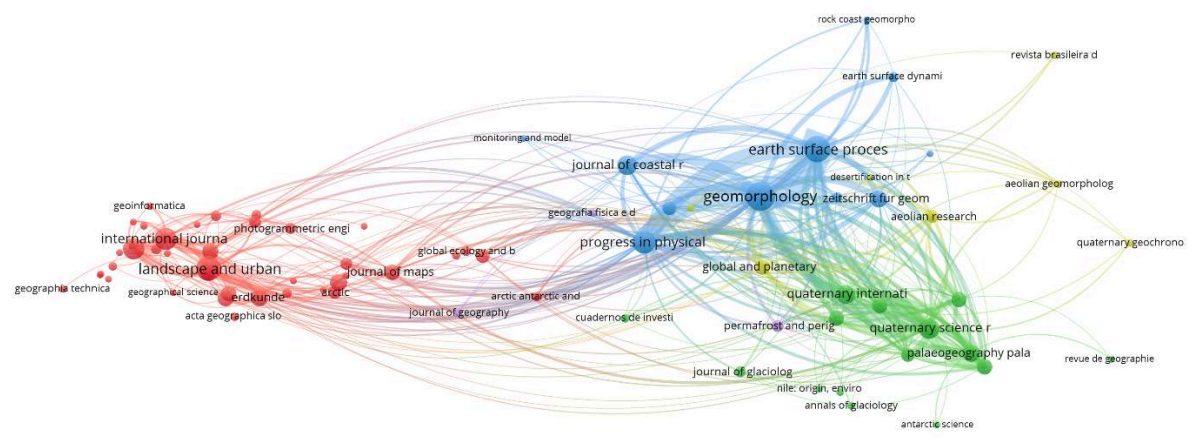

gas vosviewer

The size of the bubbles is proportional to the number of times the journal cites $\mathrm{HG}$ articles, while the lines connect journals with a higher share of bibliographic references, as a measure of similarity between two journals.

Three significant clusters compose the backbone of the map, with a fourth marginal cluster on the periphery. The first cluster (red) isolates landscape planning, landscape ecology, biogeography, and GIS science. The second (blue) and third clusters (green), which are strongly connected, concentrate the bulk of the broad geomorphology and physical geography journals on the one hand and quaternary research on the other. Finally, the fourth cluster deals with narrow regional fields of enquiry. The map testifies at least two different fronts of contact between the disciplines in PG: journals of landscape analysis and planning, together with sources of spatial sciences, and 
classic journals of geosciences. Table 2 shows the top 20 journals for number of articles published with at least one reference to $\mathrm{HG}$ articles, alongside their clusters and the average publication year of the articles citing $\mathrm{HG}$ articles.

Table 2. Top 20 PG journals citing HG articles.

\begin{tabular}{|c|c|c|c|}
\hline label & Documents & $\begin{array}{l}\text { Avg. pub. } \\
\text { year }\end{array}$ & cluster \\
\hline geomorphology & 511 & 2010 & 3 \\
\hline earth surface processes and landforms & 389 & 2004 & 3 \\
\hline landscape and urban planning & 326 & 2013 & 1 \\
\hline progress in physical geography-earth and environment & 258 & 2002 & 3 \\
\hline $\begin{array}{l}\text { international journal of geographical information } \\
\text { science }\end{array}$ & 228 & 2012 & 1 \\
\hline isprs international journal of geo-information & 185 & 2018 & 1 \\
\hline quaternary science reviews & 163 & 2006 & 2 \\
\hline journal of coastal research & 157 & 2008 & 3 \\
\hline quaternary international & 127 & 2011 & 2 \\
\hline erdkunde & 98 & 2013 & 1 \\
\hline zeitschrift fur geomorphologie & 97 & 1999 & 3 \\
\hline palaeogeography palaeoclimatology palaeoecology & 95 & 1999 & 2 \\
\hline mountain research and development & 90 & 2006 & 1 \\
\hline landscape ecology & 78 & 2013 & 1 \\
\hline erde & 75 & 2014 & 1 \\
\hline journal of quaternary science & 69 & 2006 & 2 \\
\hline holocene & 68 & 2007 & 2 \\
\hline journal of maps & 68 & 2015 & 1 \\
\hline revista de geografia norte grande & 67 & 2014 & 1 \\
\hline geografiska annaler series a-physical geography & 65 & 1996 & 2 \\
\hline
\end{tabular}


Furthermore, mapping the keywords indexed in every article allows the researcher to visualize the main topics of enquiry of a given field, together with the functional relationship among them (fig. 6)

Figure 6. Keyword map of the articles (at least 15 occurrences per word) of the dataset showing the main topic of research in PG articles citing $\mathrm{HG}$.

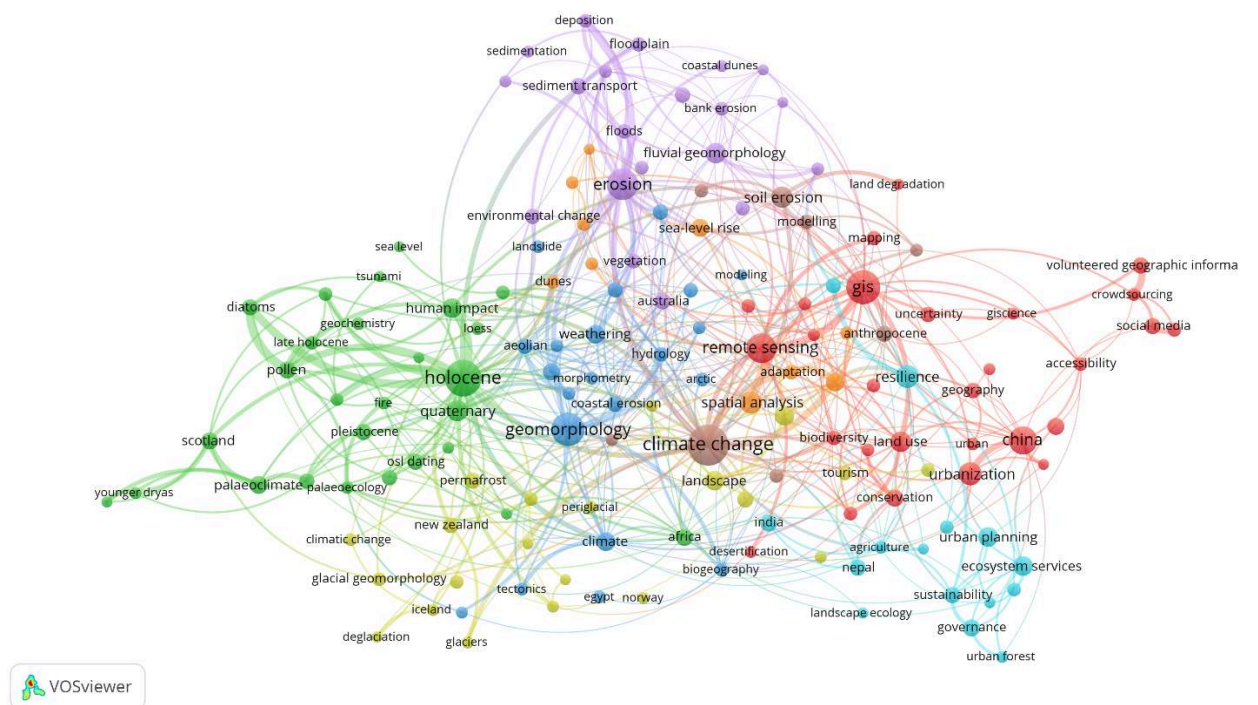

The size of the bubble is proportional to the number of times the keyword is found in the articles' metadata. The width of the lines is proportional to the number of times two keywords co-occur in the same article.

In the case of $\mathrm{PG}, \mathrm{HG}$ citations are distributed along an ample spectrum of topics and themes. Most of the keywords are part of the traditional disciplinary focus of PG, while cutting-edge keywords make their way into the map. Climate change research occupies a central place, as the most evident example of this capillary trend, acting as the scientific, and epistemic trading zone where diverse sub-disciplines intertwine. However, among the heterogeneous fold of keywords, some of the distinctive lexicon of social-sciences and HG spilled-over into the dataset: specialistic terms as "ecosystem services", "environmental justice", "political ecology", "urban forest", and "green infrastructure" make comparison as highly cited keywords, alongside with more general, but still strangers to the traditional realm of geosciences, as "social media", and "urbanization". Hence, the red cluster display the traits of a research branch deviating from the historical disciplinary norms, revolving around GIS and landscape studies.

\section{Mapping the bridges: where, and why, HG cites PG}

The replication of the experiment with the PG dataset shows the distinctive features of this common ground: the source of information retrieved in the geosciences' domain currently employed in the process of knowledge-making in the field of HG is displayed in figure 7. 
Figure 7. Network map of HG journals citing PG.

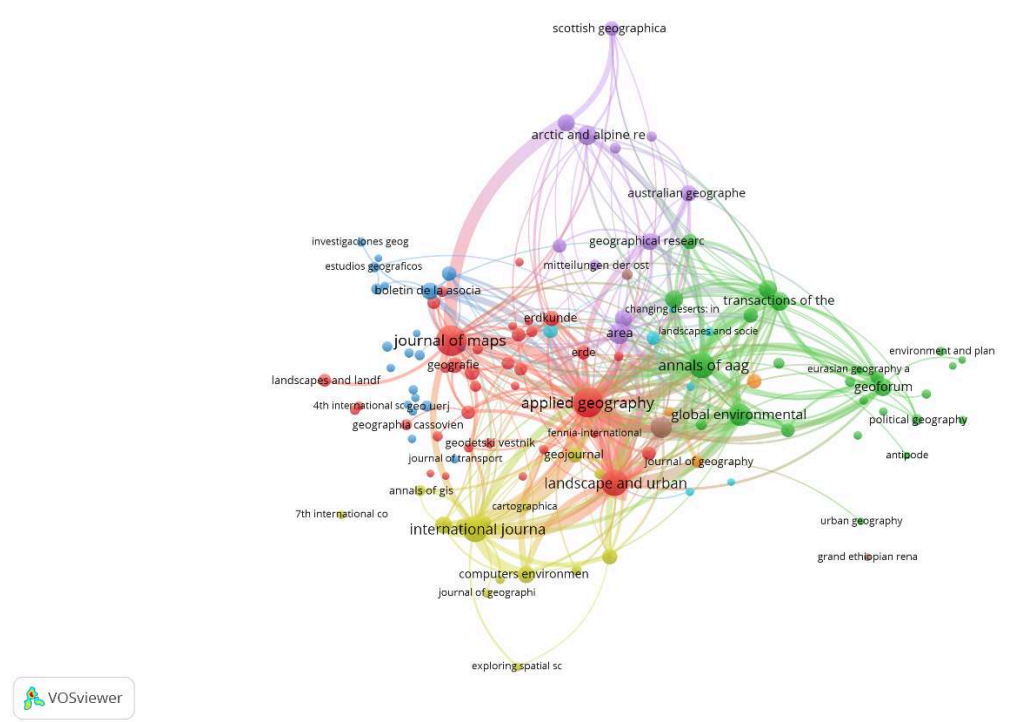

The size of the bubbles is proportional to the number of times the journal cites PG articles, while the lines connect journals with a higher share of bibliographic references, as a measure of similarity between two journals.

The map structure comprises 124 journals and is centred over the presence of five major clusters and a marginal sixth. Cluster 1 (red) concentrates journals of cartography and GIS science application alongside some tout-court geographical journals. These sources are a peculiar case (e.g. the Journal of Maps, also present in the PG dataset) publishing only research pieces employing maps as a tool of analysis and/ or representation of data; Cluster 2 (green) aggregates most tout court geography journals (the Annals, Transactions) and historically relevant specialism (Progress in Human Geography, Geography Compass). Clusters 3 (purple) and 4 (blue) build on the presence of regionalisms (the Journal of Alpine Geography, Australian Geographer, the Scottish Geographical magazine). Cluster 5 (yellow) defines a family of journals, focused on the applied dimension of the geographical sciences, whether social, economic, or digital. Journals as Transactions in GIS, Professional Geographer, Journal of Geographical Systems are all part of the cluster. Notably, Landscape and Urban Planning is also part of the HG dataset, as the journal is indexed as both a HG and PG source. Table 3 shows the first 20 sources in descending citation order, alongside their clusters and the average publication year of the articles citing HG sources.

Table 3. Top 20 HG journals citing PG articles.

\begin{tabular}{|l|l|l|l|}
\hline label & Documents & $\begin{array}{l}\text { Avg. pub. } \\
\text { year }\end{array}$ & Cluster \\
\hline journal of maps & 443 & 2015 & 1 \\
\hline applied geography & 411 & 2012 & 5 \\
\hline landscape and urban planning & 286 & 2012 & 5 \\
\hline
\end{tabular}




\begin{tabular}{|c|c|c|c|}
\hline annals of the association of american geographers & 256 & 2001 & 2 \\
\hline $\begin{array}{l}\text { international journal of geographical information } \\
\text { science }\end{array}$ & 231 & 2011 & 1 \\
\hline $\begin{array}{l}\text { global environmental change-human and policy } \\
\text { dimensions }\end{array}$ & 159 & 2014 & 3 \\
\hline arctic and alpine research & 153 & 1989 & 4 \\
\hline professional geographer & 134 & 2004 & 5 \\
\hline area & 109 & 2006 & 4 \\
\hline transactions of the institute of british geographers & 84 & 1998 & 2 \\
\hline geographical journal & 82 & 2001 & 2 \\
\hline canadian geographer-géographe canadien & 81 & 2004 & 4 \\
\hline scottish geographical journal & 73 & 2010 & 4 \\
\hline geoforum & 71 & 2010 & 2 \\
\hline singapore journal of tropical geography & 70 & 2006 & 1 \\
\hline boletin de la asociacion de geografos espanoles & 70 & 2014 & 1 \\
\hline geographical research & 64 & 2011 & 4 \\
\hline australian geographer & 58 & 2002 & 4 \\
\hline transactions in gis & 58 & 2015 & 1 \\
\hline erdkunde & 52 & 2013 & 1 \\
\hline
\end{tabular}


Figure 8. Keyword map (at least 20 occurrences per word) of the dataset showing the main topic of research in HG articles citing PG.

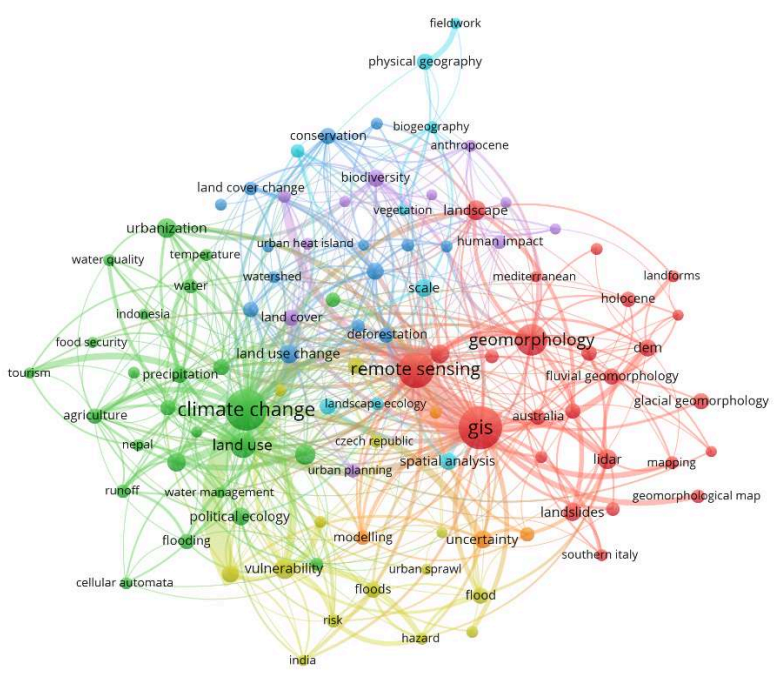

\section{B vosviewer}

The size of the bubble is proportional to the number of times the keyword is found in the articles' metadata. The width of the lines is proportional to the number of times two keywords co-occur in the same article.

A close view at the keywords composing the sample (fig. 8) reveals signs of consistency with the first map: once again the entire structure revolves around climate change, geomorphology, GIS, and remote sensing as most common topics of research.

\section{Second study: co-citation in Global Environmental Change references}

Adopting a different perspective, a co-citational analysis of a citational trading zone can reveal new evidence. Every article published in Global Environmental Change Human and Policy Dimension has been extracted, and their bibliographies are processed to obtain a complete co-citation chart. Co-citation networks involve a variety of different sources, hence a degree of reduction is needed to make sense of the data. I grouped all journals detected into nine categories, according to their disciplinary scopes (table 4).

Table 4. Categories of co-citations.

\begin{tabular}{|l|l|}
\hline Category & Description \\
\hline 0 Human geography & HG exclusive disciplinary scope \\
\hline $1 \quad$ Wide scope science & Top cited general science journals \\
\hline 2 Geosciences multidisciplinary & $\begin{array}{l}\text { Journals addressing geosciences in different disciplinary } \\
\text { domains }\end{array}$ \\
\hline
\end{tabular}




\begin{tabular}{|c|c|}
\hline 3 Biosciences multidisciplinary & $\begin{array}{l}\text { Journals addressing biosciences in different disciplinary } \\
\text { domains }\end{array}$ \\
\hline $\begin{array}{l}4 \text { General interdisciplinary natural } \\
\text { sciences }\end{array}$ & Wide scope natural sciences journals \\
\hline $\begin{array}{l}5 \text { Interdisciplinary sciences and } \\
\text { social sciences }\end{array}$ & $\begin{array}{l}\text { Wide scope interdisciplinary journals addressing both } \\
\text { social and natural sciences }\end{array}$ \\
\hline 6 Physical geography & PG exclusive disciplinary scope \\
\hline 7 Science-policy interface & $\begin{array}{l}\text { Journals addressing research on the policy dimension of } \\
\text { environmental phenomena }\end{array}$ \\
\hline 8 Extra-disciplinary specialisms & Disciplinary specialisms outside the scope of geography \\
\hline
\end{tabular}

A filter is superimposed to the analysis to limit the statistical noise, hence the study considers only papers that are co-cited at least ten times in the sample, corresponding to the third quartile in the distribution. These publications concentrate $80 \%$ of the total co-citation volume. The study evaluates then the co-citation frequency of such categories with a set of HG journals cited in GEC-HPD. The set includes HG journals that published at least one article that is co-cited ten times or more. Figure 9 summarizes the results.

Figure 9. Co-citation frequencies of HG journals and different categories of scientific journals. Total articles 39249.

Co-citation frequencies between HG journals and different journal categories

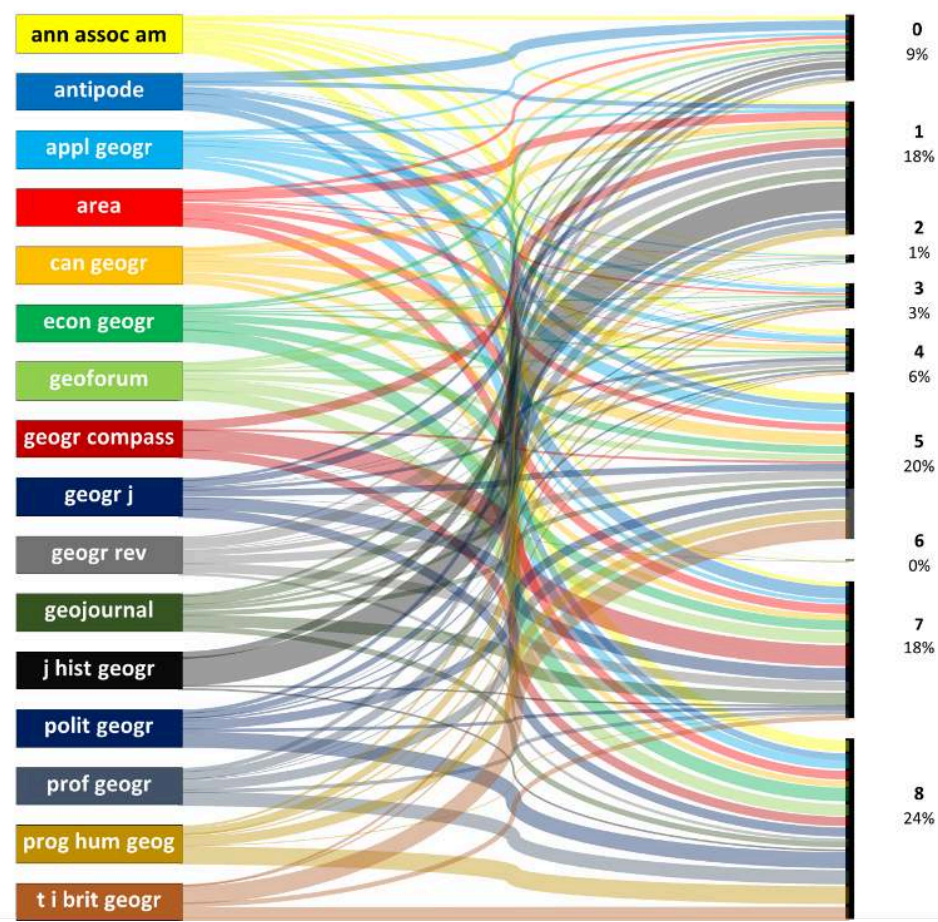


36 HG is frequently co-cited with several extra-disciplinary specialisms (24\%), interdisciplinary science and social science journals (20\%), policy journals on environmental issues (18\%), and broad scope tout court scientific journal (e.g. Nature, Science; $18 \%)$. Pure HG co-citation happens at a relatively low frequency (9\%), while cocitations with geosciences, biosciences and general natural sciences journals equal the same frequency (9\%). Finally, the fraction of co-citations between HG journals and pure PG journals is negligible, but the result should also weight in the fact that pure PG journals are an uncommon source in the publication landscape (Ferguson, 2003).

\section{The documental features of boundary research and the mobilisation of scientific results}

37 This paper explored the feasibility of scientometrics as a potential tool to enquire into the divide on a documental level, i.e., focusing on formal relationships of citation between papers and journals. The exercises delivered some new evidence that can enrich our knowledge on the divide with a new perspective. However, before delving into any interpretation of the data, it is to be remarked that the results should be read as an entry point for further research, as many other questions remain open. My findings could be checked against different volumes of literature. For instance, despite the selection of an international sample, the results display a striking majority of Anglo-American journals, which call for an in-depth comparative review of non-AngloAmerican literature, even considering publication in different languages. At the same time, a strict consideration of journal articles prevents an exploration of the citational flows between books and chapters, leading the researcher to contemplate different publishing venues.

Despite their exploratory nature, the analyses provided useful evidence to structure a reflection on the scientific relevance of geographical knowledge, both from inside the discipline (as a whole) and outside. I am offering some thoughts on three elements that arise from the analysis and might guide future research on the topic of integration between the two geographies, namely corridors, trading zones, and mobilisation of knowledge.

The first study testifies the abysmal distance that separates HG and PG on a citational level. In other words, knowledge produced on the other side of the disciplinary fences of our domain is, for the most part, hardly relevant to the conduct of our everyday scientific work. The emergence of CPG as a topic of discussion and theoretical speculation inside the community sparked some interest in our counterparts. However, any effect as a unifying paradigm at the level of publication practices is still to be witnessed. Despite the stark divide, traces of direct intellectual contact between PG and HG are recorded in the sample, as the analysis detects three groups of bidirectional citation flow between PG and HG journals. I call them corridors, as they serve as the material conduits of intellectual contact that cut their way sharply through the divide. Corridors testify the existence of spaces for codified interactions between the disciplines. The first type of corridor is provided by recognized disciplinary research journals on both sides. Coherently with the description drawn by Lave and associates, CPG might find little, yet fertile ground in this family of journals. Additionally, GIS, cartography, and mapping journals display their own and recognizable epistemological stance on the geographical sciences that look beyond divisions, focusing on the 
common interest for the spatial dimension of physical and social phenomena and the tools that come with it. Third, urban and landscape planning journals contribute to gathering and mobilising relevant knowledge from PG and HG even if they partly transcend the domain of geography.

If corridors describe the material conduits of interactions, they hardly allow the researcher to determine the nature of the information flowing through them. By contrast, keyword analysis allows locating the main topics of boundary research, detecting similarities between two otherwise distant vocabularies, providing us a glimpse of the topics that are generating an active discussion between the disciplines. Assuming keywords as an explanandum of different research strains (the explanans), Climate Change, GIS and remote sensing, and geomorphology play the role of the shared border for boundary research, or, in other words, the role of a conceptual and epistemic trading zone.

GIS and mapping constitute a notable case of inter-language trading zone (Galison, 1997), where in the case of climate change and geomorphology, the shared interest is completely organic to the normal disciplinary interest of both disciplines, as they maintain enough conceptual plasticity to be interpreted differently across scientific communities, and thus resemble boundary objects (Star, Griesemer, 1989). Even if potentially fruitful, such trading zones are unruly and spontaneous, opening the question of how to exploit the potential for co-operation in a systematic and structured fashion. As Tadaki et al. recently laid it down:

We feel that there is emancipatory potential in considering prospects for a more explicit critical turn in physical geography, and in imagining how our practices connect to others (Tadaki, Brierley, Dickson, Le Heron \& Salmond, 2015).

Taking this citation into consideration and broadening our view to the larger context of knowledge making in a multidisciplinary domain, the second study calls for some reflection on geography's place in such a process. I am not looking here at the different processes of science-making that characterize the two disciplines, and potential ways to integrate them, as an emic standpoint is certainly better suited to undertake such an endeavour. Hence, the study isolates and assess a possible integration field in terms of mobilisation of disciplinary research products in the process of knowledge creation outside of the boundaries of geography. The co-citation relationship between HG and different geo-sciences, bio-sciences, and natural sciences at large journals (categories 2, 3 , and 4 in the scheme) is far from negligible if measured in the context of an environmental science-policy journal such as GEC-HPD. There is proof of a certain degree of interoperability between the forms of knowledge considered. Interoperable forms of knowledge are easier to mobilize and travel effectively across disciplinary boundaries. Such interoperability, however, implies no obvious direct interaction between the practitioners, as the expertise of a scientific group, as well as its scientific culture, might remain black-boxed to the other groups, and therefore the encounter intrinsically non-transformational (Collins, Evans \& Gorman, 2007). Interoperability, in this case, is restricted to scientific language and products rather than practices. Hence, one should look at co-citation data as pieces of evidence of the degree in which, once mobilised by works in other research fields, HG knowledge, geo-scientific knowledge (comprising of $\mathrm{PG}$ ) and other fields of scientific literature are already being held in close contact. In this light, our data provide support to Lave's claims about the epistemic potential of CPG, as "we cannot rely on explanations grounded in physical or critical human geography alone" (Lave et al., 2015, p.3) if we are to correctly analyse and 
interpret the complexities of landscapes and environmental processes; the use of HG and PG knowledge highlighted by the case-study testifies how this concept is operationalized in the realm of environmental policy studies.

Given these final remarks, one should consider the course of action that would better fit the necessary reforms in the disciplinary publication practices. Lave et al. point at both the institution of new journals and a substantial change in the way editors select reviewers for the existing ones. Both solutions proposed are feasible but need extensive work, given the distance measured between the fields. However, the bargaining of enforced (sensu Collins et al., 2007), institutional and explicitly codified trading zones between HG and PG - following the suggestion of Lave et al., a dedicated journal - could nurture an enhanced level of scientific novelty and relevance for geography and provide an interesting testing ground for further reforms.

\section{BIBLIOGRAPHY}

BODMAN A. (1991), “Weavers of Influence: The Structure of Contemporary Geographic Research”, Transactions of the Institute of British Geographers, 16, 1, pp. 21-37

BÖRNER K., CHEN C. \& BOYACK K.W. (2005), “Visualizing knowledge domains”, Annual Review of Information Science and Technology, 37, 1, pp. 179-255.

BÖRNER K., THERIAULT T.N. \& BOYACK K.W. (2015), "Mapping science introduction: Past, present, and future", Bulletin of the Association for Information Science and Technology, 41, 2, pp. $12-16$.

BRANDES U. (2008), “On Modularity Clustering”, IEEE Transactions on Knowledge and Data Engeneering, 20, 2, pp. 172-188.

BUNGE W. (1962), Theoretical Geography. Lund Studies in Geography. Series C, General and Mathematical Geography 1, Lunde, GWK Gleerup.

CLIFFORD N. (2002), "The future of Geography: when the whole is less than the sum of its parts", Geoforum, 33, pp. 431-436.

COLLINS H., EVANS R. \& GORMAN M. (2007), “Trading zones and interactional expertise”, Studies in Philosophy and History of Science, 38, pp. 657-666.

FERGUSON R. (2003), "Publication practices in physical and human geography: a comment on Nigel Thrift's 'The future of Geography'", Geoforum, 34, pp. 9-11.

GALISON P. (1997), Image and logic: A material culture of microphysics, Chicago, University of Chicago Press.

GIERYN T. F. (1983), "Boundary-Work and the Demarcation of Science from Non-Science: Strains and Interests in Professional Ideologies of Scientists", American Sociological Review, 48, 6, pp. 781-795.

GOUDIE A. (2017), “The integration of Human and Physical Geography revisited”, The Canadian Geographer, 61, 1, pp. 19-27. 
JOHNSTON S. (2012), "Get rid of geography departments”, Geolog, 41, 1, pp. 6-7.

KUHN T. (1962), The Structure of Scientific Revolutions, Chicago, University of Chicago Press.

LAVE R. (2015), "Introduction to special issue on Critical Physical Geography”, Progress in Physical Geography, 39, 5, pp. 571-575.

LAVE R. et al. (2014), “Intervention: Critical Physical Geography”, The Canadian Geographer, 58, 1, pp. 1-10.

LEYDESDORFF L., MILOJEVIĆ S. (2015), “Scientometrics”, in WRIGHT D., LYNCH M., The International Encyclopedia of Social and Behavioral Sciences ( $2^{\text {nd }}$ Edition), Oxford.

LIVINGSTONE D. (2003), Putting science in its place. Geographies of scientific knowledge, Chicago, The University of Chicago Press.

MASSEY D. (1999), "Space-Time, 'Science' and the Relationship between Physical Geography and Human Geography”, Transactions of the Institute of British Geographers, 24, 3, pp. 261-276.

PAASI A. (2005), "Globalisation, Academic Capitalism, and the Uneven Geographies of International Journal Publishing Spaces", Environment and Planning A: Economy and Space, 37, 5, pp. 769-789.

PETROVICH E. (2020), "Science Mapping”, in Encyclopedia of Knowledge Organization, by HJøRLAND B., GNOLI C. (eds.), ISKO.

PETROVICH E., TOLUSSO E. (2019), "Exploring knowledge dynamics in the humanities. Two science mapping experiments", Interdisciplinary Journal of the History of Ideas, 16, 8, pp. 1-30.

SAAM N. J, REITER L. (1999), "Lotka's law reconsidered: The evolution of publication and citation distributions in scientific fields", Scientometrics, 44, pp. 135-155.

SMALL H. (1973), "Co-Citation in the scientific literature: a new measure of the relationship between two documents", Journal of the American Society for Information Science, 24, 4, pp. 264-269.

STAR S. L., GRIESEMER J. (1989), “Institutional Ecology, 'Translations' and Boundary Objects: Amateurs and Professionals in Berkeley's Museum of Vertebrate Zoology, 1907-1939”, Social Studies of Science, 19, 3, pp. 387-420.

TADAKI M., BRIERLEY G., DICKSON M., LE HERON R. \& SALMOND J. (2015), “Cultivating critical practices in Physical Geography”, The Geographical Journal, 181, 2, pp. 160-171.

THRIFT N. (2002), “The future of Geography”, Geoforum, 33, 3, pp. 291-298.

VAN ECK N. J., WALTMAN L. (2007), "VOS: a new method for visualizing similarities between objects", in DECKER R H.-J., LENZ H.J, Advances in Data Analysis: Proceedings of the $30^{\text {th }}$ Annual Conference of the German Classification Society, Springer, pp. 299-306.

WANSKIN B., VAN ITTERSUM K. (2016), "Boundary research: Tools and rules to impact emerging fields”, Journal of Consumer Behaviour, 15, 5, pp. 396-410.

\section{NOTES}

1. Boundary research exists on the fringes of all fields and sometimes ends up pushing these fields forward in spite of great resistance or general indifference (Wanskin, Van Ittersum, 2016). Such research often operates on blurred interdisciplinary lines that are direct result of a continuous bargaining between disciplines. Following this line, a form of integration between 
Human and Physical Geography must rely on the mutual interest needed to work at the edge of the respective scientific cultures and mainstream interests.

2. Note that WoS and Scopus require subscriptions that are usually provided by the researcher's home institutions and thus are not free.

3. https://www.scimagojr.com/

4. It expresses the average number of weighted citations received in the selected year by the documents published in the journal in the three previous years.

5. The Lotka curve describes the Lotka's Inverse Square Law of scientific productivity, generally recognized as a power law distribution. Power-law distributions have the general shape of negative exponential J-curves with a long tail to the right.

6. Even if tout-court Geography journals are open to submission for articles in PG, the number of actual PG articles published is limited due to a different publishing behaviour of PG researchers, as already noted by Ferguson (2003).

7. Note that the analysis is limited to journal articles and do not consider citations of books and chapters.

8. In bibliographic coupling, publications sharing many references, namely, publications whose bibliographies largely overlap, are considered as more similar than publications sharing few or no references at all (Petrovich and Tolusso, 2019)

9. The exercise is not repeated for PG journals as, once again, a substantially different publication behaviour (Ferguson, 2003) prevent its replication.

10. Note that the analysis is limited to journal articles and do not consider citations of books and chapters.

11. Note that the length of the time series is conditioned by the institutional subscription to the database, and not necessarily by the historical publishing life of the journal itself.

12. Despite the journal being founded back in 2012, the time series starts in 2016 due to limitations in the host university subscription to the database.

13. The case of Land is of particular interest given the wide scope of the journal, cutting through the physical and social sciences with a focus on land use, land use change and landscape, and the marked scientific diversity in the editorial board.

14. The visualization includes only sources with at least 5 documents indexed in the database.

15. Modularity is a measure of the structure of networks or graphs which measures the strength of division of a network into modules (also named clusters or communities). Networks with high modularity have dense connections between the nodes within modules but sparse connections between nodes in different modules. Modularity is a key method for detecting community structure.

\section{ABSTRACTS}

With the aim of developing a reflection on the documental level of geography, and to understand how physical and human geography are materially related, this paper analyzes an ample spectrum of indexed literature from a distant reading perspective based on scientometric tools. Moving under a sociology of science lens, the study address (I) the citational relationship between the two fields, and (II) how scientific articles in geography are mobilised and combined with different categories of research journals in a cognate scientific field. The study relies on 
science mapping techniques to chart, describe, and visualize the citational relationships among journals and fields.

Dans le but de développer une réflexion sur la production de publications de la géographie et de comprendre comment la géographie physique et la géographie humaine sont matériellement liées, cet article analyse un large éventail de littérature indexée dans une perspective basée sur des outils scientométriques. Se déplaçant sous le prisme de la sociologie des sciences, l'étude aborde (I) la relation des citations entre les deux domaines et (II) la manière dont les articles scientifiques en géographie sont mobilisés et combinés avec différentes catégories de revues de recherche dans des domaines de recherche apparentés. L'étude s'appuie sur des techniques de cartographie de la science (" science mapping ») pour tracer, décrire et visualiser les relations de référence entre les revues et les domaines.

INDEX

Mots-clés: science mapping, scientométrie, géographie physique critique, analyse de réseau

Keywords: science mapping, scientometrics, critical physical geography, network analysis

\section{AUTHOR}

\section{EMILIANO TOLUSSO}

Università degli Studi di Milano, Emiliano.Tolusso@unimi.it 